\title{
Synthesize and characterization of rice husk silica to remove the hydrogen sulfide through physical filtration system.
}

\begin{abstract}
The main goal of this study was to synthesis and characterization of silica prepared from rice husk and its application to remove Hydrogen sulfide. Polyvinyl chloride filters with $50 \mathrm{~cm}$ in height and $7.5 \mathrm{~cm}$ in diameter have been used in this study. Rice husk silica (RHS) and regenerated rice husk silica (RRHS) were used as packing material in this work. System was studied at a constant empty bed residence time (EBRT) of $60 \mathrm{sec}$ and different inlet concentration of $\mathrm{H} 2 \mathrm{~S}$ from 15 to $450 \mathrm{mg} \mathrm{m}-3$. Brunauer-Emmett-Teller method showed rice husk silica has a very high surface area $(226.3 \mathrm{~m} 2 \mathrm{~g}-1)$ with median pore radius of $2.4 \mathrm{~nm}$ and mesoporous structure. The chemical composition analysis showed that the silica consisted of $\mathrm{SiO} 2$ up to $97.35 \%$. The removal efficiency (RE) more than $98 \%$ were observed for both packed filters at a loading rate of $0.98 \mathrm{~g} \mathrm{H} 2 \mathrm{~S} \mathrm{~m}-3 \mathrm{~h}-1$ and $15 \mathrm{mg} \mathrm{m}-3$ inlet concentrations of $\mathrm{H} 2 \mathrm{~S}$. The maximum removal capacity of both packed filter were obtained $7.02 \mathrm{~m}-3 \mathrm{~h}-1$ at a loading rate of $9.0 \mathrm{~m}-3 \mathrm{~h}-1$ and $150 \mathrm{mg} \mathrm{m}-3$ inlet concentration. The result from the analysis indicates that at a $1.0 \mathrm{~L} \mathrm{~min}-1$ flow rate and different inlet concentration of $\mathrm{H} 2 \mathrm{~S}$ there is no significant difference between the RHS packed filter and the RRHS packed filter in the amount of removal efficiency and removal capacity $(\mathrm{p}<0.01)$. Also the result showed pressure drop was undetectable amount (zero) in both packed filter. The results of this study show the best performance of RHS and RRHS packed filters in low concentration of $\mathrm{H} 2 \mathrm{~S}$.
\end{abstract}

Keyword: Rice husk silica; Hydrogen sulfide; Physical filtration system; Synthesis. 